\title{
IMPROVED SEPARATION TECHNIQUES FOR THE CHARACTERIZATION OF RADIOACTIVE WASTE SAMPLES
}

\author{
April M. Meeks, John M. Keller, Joe M. Giaquinto, Tobin Ross \\ Oak Ridge National Laboritory
}

*Research sponsored by Office of Energy Research, U. S. Department of Energy, under contract DEAC-05-84OR21400 with Martin Marietta Energy Systems, Inc.

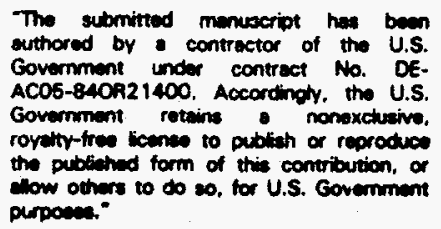

DISCLAIMER

This report was prepared as an account of work sponsored by an agency of the United States Government. Neither the United States Government nor any agency thereof, nor any of their employees, makes any warranty, express or implied, or assumes any legal liability or responsibility for the accuracy, completeness, or usefulness of any information, apparatus, product, or process disclosed, or represents that its use would not infringe privately owned rights. Reference herein to any specific commercial product, process, or service by trade name, trademark, manufacturer, or otherwise does not necessarily constitute or imply its endorsement, recommendation, or favoring by the United States Government or any agency thereof. The views and opinions of authors expressed herein do not necessarily state or reflect those of the United States Government or any agency thereof.

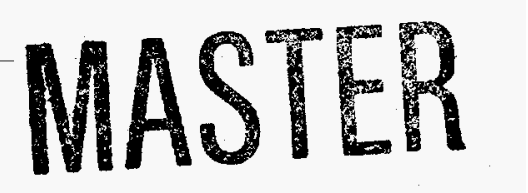

RWR/MPP

GISTREBUTTON OF THIS OUCUMENT IS URLIMUIES 


\section{DISCLAIMER}

Portions of this document may be illegible in electronic image products. Images are produced from the best available original document. 
Improved Separation Techniques for the Characterization of Radioactive Waste Samples

April M. Meeks, John M. Keller, Joe M. Giaquinto, Tobin Ross

Oak Ridge National Laboratory, P.O. Box 2008, Oak Ridge, TN 37831-6043

\begin{abstract}
Analysts have routinely used organic solvent extractions and precipitation techniques to remove matrix constituents which interfere with the characterization of radioactive waste samples. Problems with these traditional techniques involve the production of organic waste and time consuming steps. Extraction chromatography using recently developed resins manufactured by Eichrom Industries provides accuracy comparable to traditional techniques while reducing waste and time. Three types of Eichrom resins were evaluated on samples from radioactive waste tanks at the Department of Energy's (DOE) Oak Ridge National Laboratory (ORNL) for the analysis of the inorganic EPA target analyte ist elements, radioactive strontium, and radioactive technetium. Results show that extraction chromatography may be successfully applied to the characterization of DOE radioactive waste samples similar to those at ORNL, providing high efficiency, reduced waste production, and safety benefits.
\end{abstract}

\title{
Introduction
}

In many cases, radioactive waste samples resulting from DOE work are from underground storage tanks which contain both aqueous liquids and solids in the form of an inorganic sludge. The liquid phase is primarily concentrated sodium/potassium nitrate solutions at high $\mathrm{pH}(12-13)$ withhigh beta-gamma activity from caustic soluble fission products, mostly ${ }^{137} \mathrm{Cs}$. The sludge is typically a combination of hydroxides, carbonates, mixed- and hydrous- oxides, and various nitrate salts (the nitrates are mostly present in the interstitial liquid associated with the solids). The radioactivity present in the sludge includes caustic insoluble fission products (mostly lanthanides and strontium), ${ }^{137} \mathrm{Cs}$ adsorbed on the solids and present in the interstitial liquid, and the actinides (which account for most of the alpha activity present inthe waste tanks). Tanks often contain high levels of uranium and thorium which are either added for criticality control or are from various processing projects. The waste compositions to be expected from many DOE owned tanks are represented by the summary in Table I of primary components found in six of the Melton Valley andEvaporator Facility Storage Tanks (MVST) at ORNL.'

High levels of uranium and thorium and sometimes plubnium result in spectral interferences when measuring metals by Inductively Coupled Plasma (ICP). Beta and alpha activity measurements may also be complicated due to multi-radioisotope solutions and/or mass absorption from high solids content in the samples. Traditionally, spectral interferences from uranium and thorium have been removed via solvent extraction using tri-n-octylphosphine oxide or tri-butly-phosphate and octyl(phenyl)-N-N-diisobutylcarbamoyl-methylphosphine oxide (CMPO), which results in the production of hazardous organic waste. 
TABLE I. PRIMARY COMPOSITION OF MVSTS

Liquid Samples

Sludge Samples

\begin{tabular}{|c|c|c|c|}
\hline Anions & & Process Metals $^{\mathbf{a}}$ & \\
\hline Chloride & $0.059-0.14 M$ & $\mathrm{Al}$ & $830-16000$ \\
\hline \multirow[t]{2}{*}{ Nitrate } & $3.23-5.97 M$ & $\mathrm{Ca}$ & $5600-62000$ \\
\hline & & $\mathrm{Fe}$ & $420-7700$ \\
\hline Process Metals ${ }^{\mathrm{a}}$ & & K & $6100-18000$ \\
\hline$\overline{\mathrm{Ca}}$ & $3.6-23000$ & $\mathrm{Mg}$ & $870-16000$ \\
\hline K & $8500-78000$ & $\mathrm{Na}$ & $48000-82000$ \\
\hline $\mathrm{Na}$ & $61000-110000$ & $\mathrm{Sr}$ & $30-290$ \\
\hline Th & $<1.0-95.1$ & Th & $1370-12000$ \\
\hline $\mathbf{U}$ & $<0.1-1130$ & $\mathbf{U}$ & $1960-31000$ \\
\hline \multirow[t]{2}{*}{ other } & $<245$ & & \\
\hline & & $\underline{\text { RCRA Metals }}^{\mathrm{a}}$ & \\
\hline$\underline{\text { RCRA Metals }}^{\mathrm{a}}$ & & all & $<450$ \\
\hline all & $<28$ & Radioactivity $^{b}$ & \\
\hline Radioactivity $^{b}$ & & $\overline{\text { Gross alpha }}$ & $22500-223000$ \\
\hline Gross alpha & $<1.0-2140$ & Gross beta & $1440000-11000000$ \\
\hline Gross beta & $192000-2200000$ & ${ }^{137} \mathrm{Cs}$ & $194000-684000$ \\
\hline${ }^{137} \mathrm{Cs}$ & $186000-2070000$ & Eu isotopes & $<3400-1300000$ \\
\hline${ }^{90} \mathrm{Sr}$ & $412-175000$ & ${ }^{90} \mathrm{Sr}$ & $455000-5170000$ \\
\hline
\end{tabular}

a. The concentrations are given in $\mathrm{mg} / \mathrm{L}$.

b. Activities are given in $\mathrm{Bq} / \mathrm{mL}$. 
Radioactive strontium is commonly separated and purified from other beta emitters using a series of carbonate, nitrate, chromate, and hydroxide precipitations detailed in the EPA Method 905.0,Radioactive Strontium in Drinking Water. ${ }^{2}$ Common methods for isolating ${ }^{99} \mathrm{Tc}$ from interfering beta emitters and salts involve solvent extraction of $\mathrm{Tc}$ into chloroform in the presence oftetraphenylarsonium chloride. Tc may also be precipitated with tetraphenylarsonium chloride. ${ }^{3}$ These precipitation methods are tedious, requiring full attention of the analyst and can easily consume 8-16 hours of time for several samples.

Three extraction chromatographic materials manufactured by Eichrom Industries have been evaluated as alternatives to the classical methods for clean-up of radioactive wastes for analysis. The materials may be obtained commercially as pre-packed columns consisting of $2 \mathrm{~mL}$ of resin bed. Alternatively, the chromatographic resin may be purchased in bulk quantity for "in-house" preparation.

The transuranic specific material (TRU-Spec $($ ) consists of an extractant, CMPO, dissolved in tributyl phosphate supported on an inert substrate. Transuranic elements are absorbed by TRU・Spec $\otimes$ under high nitric acid conditions allowing the EPA target analyte list elements (Table II) to pass through the column and be free of spectral interferences from U, Th, and Pu for ICP analysis. Below is an example ofthe extraction equilibria observed on the column:

$$
\begin{aligned}
\mathrm{Pu}^{4+}+4 \mathrm{NO}_{3}^{-}+2 \mathrm{E} & \rightarrow \mathrm{Pu}\left(\mathrm{NO}_{3}\right)_{4} \cdot \mathrm{E}_{2} \\
\mathrm{Am}^{3+}+3 \mathrm{NO}_{3}^{-}+3 \mathrm{E} & \rightarrow \mathrm{Am}\left(\mathrm{NO}_{3}\right)_{3} \cdot \mathrm{E}_{3} \\
\mathrm{UO}_{2}^{2+}+2 \mathrm{NO}_{3}^{-}+2 \mathrm{E} & \hookrightarrow \mathrm{UO}_{2}\left(\mathrm{NO}_{3}\right)_{2} \cdot \mathrm{E}_{2}
\end{aligned}
$$

where E represents the extractant, CMPO.

Table II. Elements from the EPA Target Analyte List

\begin{tabular}{lll}
\hline Aluminum & Cobalt & Potassium \\
Antimony & Copper & Selenium \\
Arsenic & Iron & Silver \\
Barium & Lead & Sodium \\
Beryllium & Magnesium & Thallium \\
Cadmium & Manganese & Vanadium \\
Calcium & Mercury & Zinc \\
Chromium & Nickel & \\
\hline
\end{tabular}

The strontium specific resin ( $\mathrm{Sr} \cdot \mathrm{Spec} \otimes)$ consists of a crown ether, bis-t-butyl-cis-dicyclohexano18-crown-6 dissolved in 1-octanol supported on an inert substrate. Strontium is absorbed by $\mathrm{Sr} \cdot \mathrm{Spec} \otimes$ as the nitrate form under high nitric acid conditions. This purifies ${ }^{90} \mathrm{Sr}$ from ${ }^{90} \mathrm{Y}$, other beta emitters and salts. Strontium may be eluted from the column under low nitric acid conditions or water, then analyzed 
by beta counting. An example of the extraction equilibria observed on the resin is shown below:

$$
\mathrm{Sr}^{2+}+2\left(\mathrm{NO}_{3}\right)^{-1}+\mathrm{E} \leftrightarrow \mathrm{Sr}(\mathrm{E})\left(\mathrm{NO}_{3}\right)_{2}
$$

E represents the crown ether extractant.

The tetravalent actinide specific resin (TEVA-Spec $B$ ) consists of an aliphatic quaternary

ammonium salt on an inert substrate which absorbs the pertechnetate ion under low nitric acid conditions freeing it from other beta emitters and salts. High nitric acid conditions will elute technetium from the column. An example of the extraction equilibrium observed on the column is shown below:

$$
\mathrm{TcO}_{4}^{-}+\mathrm{E}^{+} \leftrightarrow \mathrm{E}^{+} \cdot \mathrm{TcO}_{4}^{-}
$$

where E represents the quaternary ammonium salt extractant.

\section{Experimental}

Each of the resins were first evaluated using standards in nitric acid media to determine accuracy and precision of element recoveries without matrix interferences. The columns were then evaluated on actual waste samples spiked with standards to measure accuracy and precision in a complex matrix. Evaluation of the TRU $\cdot S p e c \otimes$ resin for analysis of the EPA target analytes involved both radioactive and non-radioactive tracers. For evaluation of the Sr-Spec@ and TEVA $\cdot S p e c($ resins, radioactive strontium and radioactive technetium tracers were used. Sources of the radioactive tracers included radioactive calibration standards from (1) Amersham Corporation (2636 South Clearbrook Dr., Arlington Heights, IL 60005-4691), (2) process samples of fission and activation products from transuranium processing, and (3) from neutron activation of salts and oxides of EPA target analytes. All non-radioactive tracers used for ICP analysis were from the National Institute of Science and Technology (NIST).

Gamma emitting radionuclides of the EPA target analytes were counted by gamma spectroscopy on a Tennelec high purity germanium coaxial detector with a relative efficiency of $25 \%$ and a resolution of $1.85 \mathrm{keV}$. Beta counting of ${ }^{90} \mathrm{Sr}$ and ${ }^{99} \mathrm{Tc}$ tracers and tracers of the EPA target analytes not consisting of measurable gamma emissions, was performed on either a Tennelec LB-1000 alpha/beta gas flow proportional counter or by a Packard 2500 TR Liquid Scintillation Counter. For statistically efficient counting results, sample spikes of the radioactive tracers consisted of an activity to produce approximately 10,000 counts on the particular instrument, geometry, and time being used. Nonradioactive spiked samples contained $1-40 \mathrm{ug} / \mathrm{mL}$ of the tracer for analysis by a Spectroflame Model 
SAO-05 ICP Analytical Emission Spectrometer (ICP-AES) comparing visual peak heights of samples before and after extraction.

\section{EPA Target Analyte List Elements using TRU $\cdot S p e c{ }^{\circledR}$}

An aliquot $(0.1-1 \mathrm{~mL})$ of a standard solution of the EPA target analytes was added to $5 \mathrm{~mL}$ of $4 M$ nitric acid. This solution was loaded onto an Eichrom TRU•Spec@ pre-packed column which had been pre-conditioned with a $10-15 \mathrm{~mL}$ rinse of $4 M$ nitric acid. The loading solution was then rinsed through the column with $15 \mathrm{~mL}$ of $4 \mathrm{M}$ nitric acid. All of the acid effluent was collected and diluted to a known volume with distilled water. An aliquot of the effluent was then sampled and prepared for analysis by using either counting techniques or ICP-AES for the determination of analyte recovery. This procedure was performed in triplicate for each EPA target analyte list element to determine an average mean recovery and a relative standard deviation.

The TRU•Spec $®$ pre-packed column was then evaluated on an actual waste sample containing high $U$ concentration (approximately 10,000 ppm) and metals concentrations ranging from 5-200 ppm. Due to the high $U$ concentration and the capacity of the TRU・Spec® pre-packed column, 2 column extractions were necessary for the removal of $U$ from the sample. High and low spikes of the EPA target analytes were added to the samples to account for the wide range in concentration of metals already present. The high spike consisted of $8 \mathrm{ppm}$ of each analyte; the low spike consisted of $0.8 \mathrm{ppm}$. A total of $10 \mathrm{~mL}$ of sample including the spike volumes and nitric acid (added to adjust the sample to $4 \mathrm{MHNQ}$ ) was added to the pre-conditioned TRU $\cdot S p e c \otimes$ column. The column was then rinsed with $20 \mathrm{~mL}$ of $4 M$ nitric acid. Because the eluent still contained a concentration of $U$ greater than the column's capacity for $\mathrm{U}$, the eluent was diluted to $50 \mathrm{~mL}$ volumetrically. An aliquot of this eluent $(10 \mathrm{~mL})$ was added to a fresh pre-conditioned TRU・Spec@ column to remove the remaining $U$. The column was rinsed with $15 \mathrm{~mL}$ of $4 \mathrm{MHNO}_{3}$, the eluent brought to a known volume, and analyzed by ICP-AES.

\section{Radioactive Strontium using SroSpec ${ }^{\circledR}$}

An aliquot of a ${ }^{90} \mathrm{Sr}{ }^{90} \mathrm{Y}$ aqueous standard $(2.11 \mathrm{E} 4 \mathrm{~Bq})$ was added to $5 \mathrm{~mL}$ of $4 M \mathrm{HNO}_{3}$ and loaded on a pre-packed $\mathrm{Sr}-\mathrm{Spec} @$ column, pre-conditioned with a rinse of $10-15 \mathrm{~mL}$ of $4 M \mathrm{HNO}_{3}$. The column was then rinsed with $15 \mathrm{~mL}$ of $4 M \mathrm{HNO}_{3}$. The eluent was discarded. Strontium was eluted from the column with $20 \mathrm{~mL}$ of $0.05 \mathrm{MHNO}_{3}$ and taken to a known volume of $25 \mathrm{~mL}$. An aliquot of the eluent was immediately sampled and counted by beta liquid scintillation counting for determination of ${ }^{90} \mathrm{Sr}$. This procedure was performed ten times by three different analysts to obtain an average mean recovery and a relative standard 
deviation of the results.

In a second experiment an aliquot $(0.5 \mathrm{~mL})$ of an aqueous standard containing a mixture of radionuclides, including ${ }^{85} \mathrm{Sr}$ and ${ }^{88} \mathrm{Y}$, was applied to a pre-packed $\mathrm{Sr} \cdot \mathrm{Spec} \otimes$ column as described above. The $4 \mathrm{MHNO}_{3}$ rinse was analyzed as well as the strontium eluent to determine product recovery and separation efficiency. Analysis was performed using gamma spectroscopy.

In a third experiment three different waste tank samples of sludge dissolutions were appled to a prepacked Sr ${ }^{-S p e c} \otimes$ column for the evaluation of the column on a complex matrix. An aliquot of $0.1 \mathrm{~mL}$ of sludge dissolution was added to $5 \mathrm{~mL}$ of $4 \mathrm{MHNO}_{3}$ and applied to a pre-conditioned Sr$=\mathrm{Spec} \otimes$ column. The rinse consisted of $40 \mathrm{~mL}$ of $4 \mathrm{MHNO}_{3}$ which was discarded. The strontium was eluted with distilled water into a $50 \mathrm{~mL}$ volumetric flask until full. A $10 \mathrm{~mL}$ aliquot of the ${ }^{90} \mathrm{Sr}$ eluent was immediately dried on a planchet, flamed, and counted by gas flow proportional counting. Each of the three sludge dssolutions were analyzed in duplicate by this method to obtain an average of the ${ }^{90} \mathrm{Sr}$ activity in the sample and a relative standard deviation of the results. The results were compared to ${ }^{90} \mathrm{Sr}$ activities obtained by analyzing the same three sludge dissolutions by the EPA Method 905.0.

\section{Radioactive Technetium using TEVA•Spec ${ }^{\circledR}$}

An aliquot of ${ }^{99} \mathrm{Tc}$ standard $(5.0 \mathrm{E} 4 \mathrm{~Bq})$ in $0.1 \mathrm{MHNO}_{3}$ was applied to a pre-packed TEVA-Spec ( column, pre-conditioned with $10-15 \mathrm{~mL}$ of $0.1 \mathrm{MHNO}_{3}$. This step was followed with a rinse of $15 \mathrm{~mL}$ of $1 \mathrm{MHNO}_{3}$. The eluent was discarded. ${ }^{99} \mathrm{Tc}$ was stripped from the column with $20 \mathrm{~mL}$ of $8 M \mathrm{HNO}_{3}$ and taken to a known volume of $25 \mathrm{~mL}$. An aliquot $(0.05 \mathrm{~mL})$ of the eluent was counted by beta liquid scintillation counting for determination of ${ }^{99} \mathrm{Tc}$. This procedure was performed five different times to obtain an average recovery of ${ }^{99} \mathrm{Tc}$ and a relative standard deviation.

The same procedure was applied to a dissolution of a waste tank sludgespiked with varying amounts of ${ }^{99} \mathrm{Tc}$. The first spike level consisted of an amount of ${ }^{99} \mathrm{Tc}$ standard to make the final activity of the ${ }^{99} \mathrm{Tc}$ in solution equal in magnitude to the activity of ${ }^{90} \mathrm{Sr}$ and ${ }^{137} \mathrm{Cs}$ already determined in the sample. The second spike level consisted of an amount of ${ }^{99} \mathrm{Tc}$ activity two orders of magnitude lower than the ${ }^{90} \mathrm{Sr}$ and ${ }^{137} \mathrm{Cs}$ activity already present in the sample. For each spike level an aliquot $(1 \mathrm{~mL})$ of the ${ }^{99} \mathrm{Tc}$ spiked sludge dissolution was combined with $5 \mathrm{~mL}$ of $0.1 \mathrm{MHNO}_{3}$ and loaded onto a pre-conditioned TEVA-Spec $\$$ column. The column was rinsed with $15 \mathrm{~mL}$ of $1 M \mathrm{HNO}_{3}$ and the eluent discarded. The ${ }^{99} \mathrm{Tc}$ was stripped from the column with $20 \mathrm{~mL}$ of $8 \mathrm{MHNO}_{3}$, the eluent taken to a $25 \mathrm{~mL}$ known volume, and sampled for beta liquid scintillation counting. This procedure was performed five different times on each spike evel to obtain an average recovery of ${ }^{99} \mathrm{Tc}$ and a relative standard deviation of the results. 


\section{Discussion}

\section{EPA Target Analytes using TRU•Spec ${ }^{\circledR}$}

Experimental results of aqueous standards and waste samples indicated that the EPA target analyte list elements were only slightly or not extracted by the TRU・Spec® method from nitric acid media. Recoveries of greater than $90 \%$ were obtained for most analytes. Relative standard deviations obained from experiments using aqueous standards were also fairly low. Table III summarizes the results obtained for each analyte from aqueous standards and waste samples. The average percent recoveries of the analytes from aqueous standards are shown in Column 2. Also shown in this column, in parentheses, are the relative standard deviations of the analytes based upon three measurements. Accurate quantitative results were not obtained for mercury due to low counting efficiency of ${ }^{203} \mathrm{Hg}$ as a result of short half-life and low standard activity. However, extraction would not be required for the detection of mercury in regulatory samples due to the common practice of measuring mercury by cold vapor atomic absorption spectrometry. The low spike recoveries of the analytes from the high uranium waste sample are shown in Column 3 . Some of the analytes consisted of a spike amount too small to quantify relative to the concentrations of those metals already present in the sample. Those elements are indicated by an NM (not measurable) symbol in Column 3 . The silver spike recovery was not measurable due to silver chloride precipitation in the sample. The high spike recoveries are shown in Column 4. A high silver spike was not added due to the potential for precipitation. The high sodium recovery is suspected to be due to the low spike amount relative to the excessive amount of sodium already present in the sample.

Literature indicates that the theoretical maximum loading capacities of uranium, thorium, or plutonium is $25 \mathrm{mg} /$ column on the TRU·Spec $\$$ column. The literature recommends a working capacity of $10-20 \%$ of the maximum loading capacity to minimize actinide loss. ${ }^{4}$ However, if recovery of the actinides is not necessary, and only separation from the actinides is desired, $80-90 \%$ of the maximum loading capacity could be applied to the column. 
Table III. Recovery of Target Analyte Elements from TRU•Spec ${ }^{\mathrm{m}}$ Extraction

\begin{tabular}{|c|c|c|c|}
\hline $\begin{array}{l}\text { Column } 1 \\
\text { Element }\end{array}$ & $\begin{array}{l}\text { Column } 2 \\
\text { Aqueous Standard } \\
\text { \% Recovery (RSD) }\end{array}$ & $\begin{array}{c}\text { Column } 3 \\
\text { Waste Sample } \\
\text { Low spike } \\
\text { \% Recovery } \\
\end{array}$ & $\begin{array}{c}\text { Column } 4 \\
\text { Waste Sample } \\
\text { High spike } \\
\text { \% Recovery } \\
\end{array}$ \\
\hline Aluminum(III) & $101 \quad(9)$ & NM & 101 \\
\hline Antimony(III) & $100(<1)$ & 99 & 100 \\
\hline Arsenic(III) & $100(<1)$ & NS & NS \\
\hline Barium(II) & $94 \quad(2)$ & 97 & 100 \\
\hline Beryllium(II) & $101(11)$ & 102 & 99 \\
\hline Cadmium(II) & 104 (5) & 90 & 103 \\
\hline Calcium(II) & $100 \quad(9)$ & NM & 98 \\
\hline Chromium(III) & $93 \quad$ (2) & 77 & 103 \\
\hline Cobalt(II) & $103(3)$ & 100 & 103 \\
\hline Copper(II) & $101(10)$ & 96 & 100 \\
\hline Iron(III) & $96 \quad(6)$ & NM & 103 \\
\hline Lead(II) & $108(6)$ & NS & NS \\
\hline Magnesium(I) & $99 \quad(10)$ & NM & 101 \\
\hline Manganese & $99 \quad(<1)$ & 99 & 102 \\
\hline Mercury(II) & $101(19)$ & NS & NS \\
\hline Nickel(II) & $86 \quad(5)$ & $\mathrm{NM}$ & 98 \\
\hline Potassium(I) & $95 \quad(6)$ & 102 & 102 \\
\hline Selenium & $97 \quad(2)$ & NS & NS \\
\hline Silver(I) & $96 \quad(4)$ & NM & NS \\
\hline Sodium(I) & $96 \quad(5)$ & NM & 121 \\
\hline Thallium & $99 \quad(1)$ & NS & NS \\
\hline Vanadium(IV) & $99 \quad(11)$ & 104 & 102 \\
\hline Zinc(II) & $97 \quad(2)$ & 92 & 100 \\
\hline
\end{tabular}

RSD represents the percent relative standard deviation based upon three measurements. NM represents elements which were not measurable due to relatively low spike. NS represents elements which were not added as a spike to the sample. 
Radioactive Strontium using SroSpec (

Experimental results from the application of aqueous standards of ${ }^{90} \mathrm{Sr} /{ }^{90} \mathrm{Y}$ indicate that efficient recovery of strontium can be obtained. Based on ten measurements, an average recovery of $101 \%{ }^{90} \mathrm{Sr}$ with a relative standard deviation of $1 \%$ was achieved. Experimental results from the application of an aqueous mixed radionuclide standard to the column showed thatefficient separation of the strontium from yttrium and other nuclides can be achieved. Recoveries of these nuclides in the high nitric acid wash and the strontium recovery in the low acid wash are shown in Table IV. Table V compares ${ }^{90} \mathrm{Sr}$ results of waste samples applied to the Sr-Spec $B$ column to waste samples analyzed by the EPA Method 905.0. These results are comparable.

Careful attention must be used not to exceed the loading capacity of the column for strontium when analyzing samples. Literature indicates that the maximum capacity of the column is $25 \mathrm{mg}$ of strontium. ${ }^{5}$ It is recommended in Eichrom product brochures hat only 10-20\% of the maximum capacity be loaded for accuracy and minimal loss of the isotope.

Table IV. Mixed Radionuclide Recovery on Sr`Spec® Column

\begin{tabular}{|c|c|c|}
\hline Nuclide & $\begin{array}{c}4 \mathrm{MHNO}_{3} \text { eluent } \\
\% \text { Recovery }\end{array}$ & $\begin{array}{c}\text { DI } \mathrm{H}_{2} \mathrm{O} \text { eluent } \\
\% \text { Recovery }\end{array}$ \\
\hline \hline Am-241 & 93 & 0 \\
\hline Cd-109 & 93 & 0 \\
\hline Co-57 & 93 & 0 \\
\hline Ce-139 & 100 & 0 \\
\hline Sn-113 & 95 & 0 \\
\hline Sr-85 & 0 & 95 \\
\hline Cs-137 & 98 & 1 \\
\hline Y-88 & 98 & 0 \\
\hline Co-60 & 98 & 1 \\
\hline
\end{tabular}

